\title{
6 \\ Organisational Leadership: Expanding the Multicultural Arts Milieu
}

Organisational leadership refers to mainstream or small to medium (S2M) arts organisations that combine their influence and resources with those of non-English speaking background (NESB) artists or multicultural arts organisations to produce and present new work. Creative and organisational shifts occur in the arts environment when these partnerships become part of an organisation's regular program of activities. NESB artists are able to challenge the conventional art binaries of 'tradition' and 'contemporary' and disrupt the temporal trope that creative change 'will take time'. As Papastergiadis $(2005,40)$ observes of diasporic and Indigenous visual artists working in the mainstream: 'Their practice and status question the dominant assumption on the relationship between traditional authenticity and contemporary culture and test the limits of artistic agency and institutional structures'.

'Test[ing] the limits' is the basis of the creative process and can also challenge the capacities of arts organisations to manage difference. Artists confront issues of creative compromise and how to work within an unfamiliar structure. Organisations confront the challenges of new forms of production and content and how to engage with different audiences and expand existing audiences. I argue that the energy generated through these interactions and processes can lead to systemic change. I also argue that there are different modes of leadership and different approaches within those modes. In particular, relational, transformational and 
transactional leadership modes are all pertinent here. These leadership modes can manifest through various processes, including attunement, accompaniment and charisma. This chapter analyses how new forms of creative partnerships can change how NESB artists work with mainstream arts or their tributaries to produce and present their work. I argue that the arts sector generates a refreshed multicultural arts milieu when creative and organisational leadership are consistently combined. The milieu can re-form to accommodate creative leadership for multicultural arts practices as they exist and evolve.

This focus on arts organisations provides glimpses into the crucial infrastructure platform that enables the development and presentation of creative work. These glimpses reinforce that it is NESB artists themselves who must show creative leadership to 'make a new door' (Badami 2017) and work in concert with arts organisations that have the capability to produce their work. Artists navigate the void left by the significant redirection of federal and state funding away from multicultural arts organisations (see Table 4) and, also, the absence of a national creative hub for multicultural arts practices. Demonstrating both boldness and attunement, NESB artists work in conjunction with established arts organisations to expand creative opportunities and leadership skills for themselves and the wider artist community.

The confluence of productive, creative and organisational leadership can improve diverse art production and produce creative possibilities for NESB artists, along with the active dissemination of their work. The case studies in this chapter include the development of the relationship between independent artist Shakthidharan and Carriageworks and Belvoir Street Theatre Company, two major producers and presenters; the struggle by kultour for multicultural organisational independence, demonstrating the development of trust found in collaboration; and the joining of forces of a small company, Contemporary Asian Australia Performance (CAAP), with an arts industry organisation, Playwriting Australia (PWA). These examples explore how small, creative and organisational interventions can open up artistic practices to produce new and innovative artforms and different narratives about Australian society. 


\section{Turning Friction towards Sustained Interaction}

Sustained and productive interaction between NESB artists, arts organisations and audiences generates creative opportunities that respond to the challenge of how to go 'beyond the instrumental' (Blonski 1992, 3). The issues of long-term change that gave rise to this challenge remain as valid today as ever, as Blonski (2017, email) comments:

We felt that a deeper engagement was essential, but the concern also was how fragile this could be long-term. We were working within a period where there was a lot of writing and very interesting work being created. But we were all aware of how fragile this was. Building long-term support-financial, infrastructure, intellectual—was important but the question was, how to do it?

The skill to develop successful long-term support and relationships to be able to work in concert requires all parties to do the 'work' of diversity (Noble 2009, 51) — that is, to take the extra care and attention to produce a creative product or outcome that is more than a token presentation. Inclusion in a program can risk being tokenistic if the artist inhabits 'institutional spaces that do not give you residence' (Ahmed 2012, 176). A lack of residence can produce forms of tokenism in which cultural difference simply becomes a form of exotica to be savoured by the mainstream population as a form of 'cosmo-multiculturalism' (Hage 1997, 14). Hage $(1997,17)$ refers to the results of this as:

Multiculturalism without migrants: a multicultural reality made of institutions that seem to exist without any migrant subjects to sustain it. In the process, it is somehow 'forgotten' that multiculturalism in Australia is, or at least ought to be, above all about migrant lives and inter-cultural interaction.

This forgetfulness is still to be found in many arts organisations today, and in their audiences. A more collaborative mode, by comparison, enables and presents art that enhances the work of NESB artists by placing it within the arts sector, not outside it. The artist and the organisations are active in producing creative 'intercultural interaction'. If consistently maintained, this method will generate artistic legacies that mobilise a more dynamic multicultural arts milieu and one that can be better linked to 'mainstream arts' as well as profile 'marginal arts'. 


\section{Making Multicultural Content Resident in Australian Art}

The steps towards generating substantial accommodation for multicultural arts practices afforded by intercultural interactions could begin by identifying 'confluences of knowledge, as well as the nodes of practice and discourse informed by those confluences' (Tsing 2005, 113). To identify such nodes is to identify the places of creative communication and production that position and enable NESB artists to generate the creative and economic 'equitable power' that Shakthidharan (discussed below) wants to experience. Identifying how these 'nodes of practice' resonate with the range of practices NESB artists engage with, particularly those at the most precarious creative edges, brings the contemporary into dialogue with ethnic and migrant traditions. Smith (2006, 695-96) sees contemporary art not as 'persistent modernist formalism' but in the internal changes in the art of the 1960s and 1970s from a 'world reshaped by decolonisation and incipient globalisation'. An appropriate articulation of the 'contemporary' is exemplified by curator Okwui Enwezor's 2002 Documenta 11, an international exhibition held every five years. Documenta 11 was based on ideas of 'transculturality and extraterritoriality' and was 'less a receptacle of commodity objects than a container for a plurality of voices, a material reflection on a series of disparate and interconnected actions and processes' (Enwezor 2002, 55).

The concept of 'accompaniment' is helpful here. Accompaniment joins individuals and groups with those with power and influence to generate new ways to achieve change. The crucial element is that accompaniment is an equal process in which skills and knowledge are equally valued. 'Attunement' presents another way to progress intercultural interactivity through close and adaptive listening. 'Confluences of knowledge', 'accompaniment' and 'attunement'-three concepts discussed earlier in this text-suggest that leadership can interact and contribute to an expanded multicultural arts milieu.

\section{Enduring Enthusiasm: Counting and Cracking}

Imagine a scenario in which an independent NESB artist is invited to make a work with a producing and presenting arts organisation. This opportunity raises issues of how to negotiate and present creative content that is outside the mainstream canon. For the organisation, this is a means 
to directly support the creation of work, expand their repertoire, be relevant in Australia and diversify their audience. The following case study looks at the initial collaboration of aspiring playwright Shakthidharan and Carriageworks, a major art centre and venue in the gentrified inner suburb of Redfern, New South Wales. Their project is an example of cultural innovation whereby 'the emphasis is on the creativity of the artist in the generation of innovative work to extend the focus of cultural expression' (Mar and Ang 2015, 6).

Extending that focus is enabled by at least two principles: first, by enhancing inclusive curatorial processes; second, by supporting a diversity of cultural expressions (Mar and Ang 2015, 7). In 2015 Carriageworks achieved both through its associate artist and resident company projects. Carriageworks and CoCurious wants the organisation to be inclusive and creatively relevant to its social and cultural environment. Therefore, she aims to:

Support local artists to work more ambitiously around scale and audiences, and put their new work in the right contexts. And then place them within a program with international artists that might make pathways for them. (L. Havilah 2015, interview)

Havilah's programming is endorsed by the arts sector. The director of the Sydney Chamber Opera, a resident company at Carriageworks, commented: 'Carriageworks has come to be seen where contemporary art is at in all its manifestations' (Symonds quoted in Taylor 2017).

Havilah began her career by establishing an artist-run initiative at Wollongong, southern NSW, and she has held influential roles at the Casula Powerhouse Arts Centre, Liverpool, and at the Campbelltown Arts Centre. As Carriageworks CEO, at the time, Havilah introduced a number of initiatives that contribute to artists' professional development, including the establishment of the intermediary role of co-producer and providing associate artists with access to professional networks, mentoring, and time and space in which to develop a piece. Artist-in-residence programs offered by many organisations across all artforms provide space and time for artists to develop new projects; however, Carriageworks offers artists the space and opportunity to do a presentation at the end of their residency, even if their work is still in progress. Shakthidharan was selected as the inaugural associate artist from 2013 to 2015 because he seemed: 
Like an artist who would take advantage of a high level of support and mentorship. I was interested in what he would develop and what he represents regarding Western Sydney and how he works internationally. (L. Havilah 2015, interview)

Here Havilah supports Shakthidharan's creative ambitions, identifies the relevance of Western Sydney for many NESB artists and values the potential to expand international relationships. Themes of collaborating with community, growing up in the digital revolution and working in Western Sydney are the main influences on Shakthidharan's modes of creative production. Of particular relevance here is how he bridged his practice(s) into a professional career as a playwright. As an artistic associate at Carriageworks, he gained access to mainstage organisations through a combination of dedication, connections and opportunities. His productive residency led to negotiations with mainstage company Belvoir Street Theatre (Belvoir) for an epic, multigenerational play set in Sri Lanka and Australia:

Through their journey, we see a Sri Lanka riven by, but no means surrendering to, violent divisions-and an Australia transforming of, but also transformed by, the people that flee to its shores. (CuriousWorks n.d.)

Counting and Cracking has seen many iterations since its first development grant in 2009, but Shakthidharan has stayed true to his original intention to encompass four generations of a family's resettlement from Sri Lanka to Australia. Maintaining the epic narrative format could be considered a literary form of the 'vernacular cosmopolitan' (Gunew 2017b, 33-52), acknowledged in creative terms as 'not an easy road' (Gunew et al. 2017, 596). The concept of the 'vernacular cosmopolitan' as proposed by Homi Bhabha (Werbner quoted in Gunew 2017b, 33) is a "cosmopolitan community envisaged in marginality", a border zone'. The term can be stretched to encompass the exchange of family and community-based knowledge as a way of extending openness through artworks by NESB artists. Even though Gunew et al.'s $(2017,595)$ focus is on cultural diversity and literature across a range of diasporas, their observations translate to playwriting about vernacular cosmopolitanism, particularly when they describe literature by migrant writers as 'a palpitating absence, you feel it, quivering and these absences are clamouring to be made visible'. 
The evocation of clamour suggests a friction that demands attunement as well as accompaniment to publish more NESB writers. Making these absences visible is the intention of the collaborative processes described in this chapter that join creative aspirations with organisational support and know-how. Those stages leading to greater visibility can be tenuous for the NESB artist:

Lisa [Ffrench, director of programs at Carriageworks] read the play, no one would read it because it's 190 pages long, and gave it to Chris Mead, artistic director of Playwriting Australia and [who at that time worked] in the [Carriageworks] building. Chris loved it, but he moved to MTC [Melbourne Theatre Company]. Meanwhile, Carriageworks supported a development of the play, and Eamon Flack, [director of Belvoir in Surry Hills, NSW] came to a reading both through my pestering Belvoir and Carriageworks' contacts. I didn't realise at the time, but he liked it. We also had a reading with Melbourne Theatre Company, but I think they thought it was one bridge too far. (S. Shakthidharan 2015, interview)

This comment highlights several aspects of development and production in theatre production. The decision-makers frequently move on and only occasionally bring projects of interest with them. This instability produces a stop-start scenario for artists seeking the right partners to see a project to completion. Keeping track of existing partners, and the need to find new ones, requires persistence and an ability to maintain a high level of enthusiasm for the project. It also demonstrates tenacity in staying true to the original impetus. Sustained effort is required to maintain momentum, which, for the NESB artist, as Ahmed $(2012,186)$ observes, 'might appear to others as stubbornness, willfulness or obstinacy'.

For Shakthidharan, leadership 'at our end of the spectrum'-that is, not the major performing arts (MPA) companies or the 'big end of town'-means being able to achieve a mutual vision despite setbacks and differences, and avoiding the creative danger of repeating the same style and type of project. His persistence aims to effect long-lasting change in the arts sector by establishing how to navigate difference in the arts:

Success can be gauged by finding a mutual vision with people who are very different from you. Sometimes people in SMEs [small to medium enterprises] or groups of multicultural artists will band together, and they'll find solidarity with each other, but they're polarising. Sometimes you have to figure out the difficult way to work with people who are very different to you because that's the 
only way it will change. Otherwise, you end up accepting that is how it is, and that your only role in all of this is to complain. And I don't want to be that person. I want equitable power. (S. Shakthidharan 2015, interview)

Shakthidharan wants action. He eschews the essentialised role of the 'whingeing wog' (L. Marinos 2015, interview) and tries to work with people who are 'very different to you'. In this context, he speaks of working with people in very different organisational structures as well as different sociopolitical, cultural and creative perspectives. His analysis of what will make change draws on the 'permeable' quality of the relationship between organisations and people. He goes further in identifying what he feels will not work-in particular, that 'banding together' will not be enough to produce change. Although multicultural arts organisations do successfully 'band together' to support and find 'solidarity with each other', Shakthidharan thinks this is no longer enough. He feels it is important that those in leadership roles in multicultural arts organisations engage with those in positions of power to negotiate 'equitable power'. This constitutes a challenge that writer Olubas (quoted in Gunew et al. 2017, 588) describes an 'impossible negotiation'. The situation is one in which NESB artists are the only ones to make culturally diverse work, but, at the same time, the industry perception is that 'you don't need anything special, further time or attention because you already have it' (Gunew et al. 2017, 588). Attention is, however, required and includes economic, infrastructure and dramaturgical input around the aesthetic considerations of the work.

Shakthidharan observes that when a director is mounting a Shakespearean work, for example, the familiarity of the text means the director need only consider aesthetic and production values: 'They're likeaesthetically what am I trying to do here? That's all they need care about' (S. Shakthidharan 2015, interview). In a similar vein to Annalouise Paul's concerns (see Chapter 4), the aesthetics of intercultural work bring to the fore a range of new considerations that Shakthidharan (2015, interview) thinks must be treated carefully:

My background is Tamil Sri Lankan and is influenced by classical Indian aesthetics and subcultures from south India, which is the Tamil connection. In Tamil classical aesthetics, there is an interrelationship between mood, humans and the environment. The question is how to subtly get the aesthetics of the cultures that are contributing to that work into our productions. 
Shakthidharan touches on some of the areas to which he must be attentive. $\mathrm{He}$ acknowledges the challenge of using finesse to generate a classical mise en scène within a contemporary work. However, to subtly 'get' the subcultural aesthetic identifies a hierarchy of cultural artefacts that cannot be represented so subtly. In his description, subtlety appears as a type of friction in which aesthetic elements slide over one another, when, in fact, epic family narratives may require more bumps and circumnavigation to bring their dynamics to life. No reason is given for the need to be subtle, but it does suggest a tension around the question of how much ethnicity can be presented on the mainstage. This is similar to the criticism that the dominant culture will complain about 'too many' Asians/Moslems/Syrians (Hage 2000, 39). This aesthetic issue also resonates organisationally because, as the 'placement' NESB artist in a predominantly AngloAustralia company, Shakthidharan may be challenged to 'fit in' and might not adequately 'bring in' his perspective if the performing arts environment he is working in 'rewards a focus on a dominant Anglo perspective' (Caprar 2018). Regardless of Shakthidharan's final choices and possible compromises, his point highlights how these details preoccupy the NESB artist when making a work they hope will become part of the Australian mainstream canon.

The cultural specificities of Shakthidharan's work require a translation across cultural modes that are unfamiliar to most audiences. The vehicle of four generations of a Sri Lankan (Tamil) Australian family suggests, at first, a bicultural piece that brings different dimensions of social, political, economic and cultural experiences into dialogue with each other. However, the potential for other layers to emerge through the matrix of 'mood, humans and the environment' (Shakthidharan, interview 2015) presents an opportunity for an aesthetic exploration that produces a hybrid outcome that goes beyond just an encounter between two cultures. To a large extent, Australian theatre has accepted the somewhat prescriptive vehicle of the first-generation migrant family 'suitcase' story (Kelly 1998). In the case of Cracking and Counting, the involvement of several generations alters that paradigm to complicate migration patterns and its impacts. It also has the potential to utilise the range of Tamil and Tamil-Australian aesthetic ethoses as a way to portray the experiences of migration to Australia.

Visual artist Tania Bruguera refreshes considerations of aesthetics to draw out the ethical dimensions of a cross-cultural or intercultural practice. Bruguera's (quoted in Donovan 2011) work concerns the 'role of the artist 
in society' in relation to organisational processes. She identifies a shift towards a greater ethical consideration as to how artists access the resources of major arts organisations. Issues of how ethics are taken into account in aesthetic decisions acknowledge the increased complexity for an artist like Shakthidharan when developing a new intercultural family epic. This is a type of relational leadership utilised by many NESB artists as they engage with their sources of inspiration and wield the infrastructure of an organisation unfamiliar with those sources.

The major organisations involved in the development of Counting and Cracking were Carriageworks (Carriageworks n.d.) and inner-city Sydney theatre company Belvoir (Belvoir n.d.). Shakthidharan and Belvoir matured Shakthidharan's aim for Tamil and Tamil-Australian aesthetic experience. This process contributes to a more robust multicultural arts milieu that alters how creative and organisational leadership becomes apparent. This approach is one way to provide 'meaningful, committed, resources, [in the] long-term process of shifting existing power dynamics' in Australian theatre (Canas 2017). As Shakthidharan (2015, interview) says, 'I want kids to be able to read my work as part of their curriculum. I had nothing like that growing up'.

The friction in the evolution of Counting and Cracking is one of subtle and steady sharing of experiences between a seasoned company director and an emerging playwright with a particular knowledge of cross-cultural media production. It is a friction that lends itself to crafting creative outcomes, rather like the slow and steady process of woodcarving. The play was slated for the 2019 Belvoir season. CuriousWorks profiled it thus:

This is a stylised, epic drama about love, violence, silence and hope in families-all from the perspective of the insiders. In presenting the vastly different worlds of Sri Lanka in the midlate 20th century and Australia in the early 21st century, Counting and Cracking ultimately shows how much we have in commonbetween generations, countries and ourselves—and the surprising consequences that flow from that. Writer/Co-Director: S. Shakthidharan; Director Eamon Flack. (CuriousWorks n.d.)

The use of 'surprising consequences' aims to generate curiosity and suggests there may be something beyond the safe trope of 'commonality'. The credit includes Shakthidharan as co-director-a triumph because co-directing formed part of his early negotiations with Belvoir. Unlike 
some playwrights, Shakthidharan would not simply hand his text over; instead, he wanted to co-direct to maintain cultural appropriateness and the 'spirit' of the work. His claim for equal power was a step in what he perceives as the right direction. Belvoir may consider what they need to do to have more works like his in the pipeline so that co-produced plays become 'business as usual' rather than the occasional burst of attention. The company may also reflect on how this project has impacted the organisation and what they may carry forward into future programming.

Exchanges of expertise need to consider both the artist and the company. Both parties are trading technical, cultural and ethical knowledge. Both parties are experiencing and overcoming small frictions and simultaneously learning from each other. Both parties are also learning how to trust in private and then trust creatively in public. Shakthidharan had to invest as much in training Belvoir in epic Tamil-Australian aesthetics as Belvoir had to invest in training Shakthidharan in the constraints that make a theatre production of that scale successful. This case demonstrates those 'unpredictable interfaces' (Mar and Ang 2015, 8) as an intercultural exchange that produces both creative and cultural outcomes. It also represents a public outcome in a traditional theatre space, which is another interface to be navigated in bringing new audiences to the theatre (Kapetopoulos 2004). These creative constraints shape the final work to increase audience and creative reach. At the same, they understand that:

[To] recognise diversity requires that time, energy, and labor be given to diversity. Recognition is thus material as well as symbolic: how time, energy and labor are directed within institutions affects how they surface. Diversity workers aim to intervene in how the institution surfaces. (Ahmed 2012, 29)

As to how the creative precariousness of Counting and Cracking may 'surface' in the theatre world has been a case study in complexity, negotiation and persistence. In 2017 Shakthidharan could say, after more than 10 years, that the play was slated for 2019, and that, 'so far, so good, things are developing well and overall it's been a great experience':

Eamon [Flack] is directing, I'm writing and co-directing. The creative process has been excellent as we've met as equals and developed the work with respect for what it needs to be. (S. Shakthidharan 2017, email) 
This comment indicates that Shakthidharan's relational leadership and 'diversity worker' role, in combination with Belvoir's efforts, have been productive. Belvoir receives funding for their productions; however, Counting and Cracking required additional funding, suggesting that this type of work has yet to become 'business as usual':

It has been tough raising the money for the work as it is so ambitious-it's a family epic with a big cast. Both companies are operating out of their 'business as usual' paradigms to make a project like this happen, which have required persistence and flexibility from both of us. (S. Shakthidharan 2017, email)

There is a danger that Shakthidharan is, to an extent, a 'volunteer creative' on the project. This common power imbalance in employment is yet to be righted for the majority of NESB artists.

Shakthidharan was the beneficiary of a Carriageworks residency that went the extra step when Havilah 'brokered' an introduction by recommending his work to Belvoir. In this sense, Shakthidharan and Havilah are both diversity practitioners - 'people who want diversity to go through the whole system' (Ahmed 2012, 29, original emphasis). Shakthidharan wants to have his play produced on his terms on the mainstage and promoted as such. Havilah (2015, interview) claims that Carriageworks uniquely programs artworks across the spectrum of what constitutes 'diversity': 'I don't think, other than Carriageworks, there's a major cultural institution that holds diversity at its core. And I think that's a big issue'.

Counting and Cracking was presented by Belvoir (co-directed by Eamon Flack and S. Shakthidharan and co-produced by Belvoir Street and Co-Curious) at the 2018 Sydney Festival and at the 2019 Adelaide Festival of Arts. Testament to the persistence and creative leadership of those involved, the critical acclaim with which it was met was matched by industry accolades. Counting and Cracking went on to win seven out of eight national theatre awards at the 2019 Helpmann Awards, including Best Direction, Best Female Actor in a Supporting Role, Best Male Actor, Best Production and the overall award of Best New Australian Work (Helpmann Awards 2019). Shakthidharan (quoted in Boland 2019) commented:

Eamon and I don't live in the same part of Sydney, we don't work for the same sort of companies, and we've had very different types of upbringings, but there's a strange power that emerges when people who aren't supposed to work together, work together. 
Australia is at a bit of a crossroads and everyone's telling us the best-case scenario is that we retreat into our tribes and tolerate each other or we can take a deep breath and keep walking along this type of path and embrace the messiness of solidarity.

This case study is one in which resilience and persistence have gone hand in hand-as has the vision and proactive brokerage on the part of Carriageworks and CoCurious with Belvoir. Persistence is a necessary attribute of the diversity practitioner (Ahmed 2012, 30). Shakthidharan, while working with Carriageworks and in his subsequent segue to Belvoir, was a recruit who could 'both renew and restore' the organisation (Ahmed 2012,39). Counting and Cracking has the potential to renew the relevance of Australian theatre, extend to a broader audience and restore the creative dynamics in theatre production.

This illustrates Shakthidharan's relational leadership with a wide range of players, including his extended Tamil-Australian family, who are unused to 'Western style' theatre. The process of 'accompaniment' is present in the equal sharing of skills and knowledge between director and playwright. The process of 'attunement' is evident in the playwright working with his extended family to develop the play and, in particular, his attempt to bring their aesthetics and experiences to the mainstage. The overall intention appears to be one of establishing productive relations at the centre of both the creative project and the organisation.

\section{Establishing Trust through Organisational Collaboration}

The capacity to activate networks is viewed as a core leadership skill. Being isolated from arts sector and creative networks is a consistent theme articulated by NESB artists. This is supported by research conducted in 1998 that identified the need for peer support and artistic opportunities (Positive Solutions n.d.). These factors, coupled with a lack of contact between the fragile, overworked, state-based multicultural arts organisations, led to the Arts in a Multicultural Australia (AMA) 2000 policy initiatives aimed at alleviating these issues (Keating, Bertone and Leahy n.d.). This section analyses one such initiative: kultour, a national program that promoted the work of NESB artists and multicultural arts content and demonstrated capacity building for leadership in multicultural arts practices. I argue that the previous benefits to NESB artists and 
organisations through a dedicated national multicultural touring network are not entirely satisfied by occasional inclusion in mainstream arts touring programs.

\section{The Funded Network: kultour}

Kultour was one of the significant funded initiatives of AMA 2000 and 2006 that brought creative and organisational leadership elements together. This national network exchanged artworks as a way for organisations to support each other and to expand their experience and that of the artists through a working relationship (kultour 2015). Kultour was established to address the isolation of NESB artists and multicultural arts organisations through peer interaction and national touring programs. It existed as a network across Australia from 2001 to 2014 (Diversity Arts Australia [DARTS] 2018). The program was established to give legitimacy to NESB artists and their support organisations. The kultour network aimed to alleviate some of the tensions between the multicultural specific organisations and the better-resourced arts mainstream. It exemplifies distributed leadership in which members are called upon to play to their strengths and lead as the project requires. I suggest that being part of a network increases artists' confidence and helps them form functional relationships from which they can identify opportunities and form collaborations that lead to new creative endeavours. 'Network expertise' includes brokers who are 'located on the margins of communities or well-placed information keepers [who can identify] opportunities to broker' (Carmichael 2011, 49). This expertise 'represents relational competencies that emerge through co-evolution of individual and distributed cognitions' (Hakkarainen et al. quoted in Carmichael 2011, 49). In this context, kultour members can be seen as multi-sited brokers who distributed their knowledge to realise opportunities for creative presentation.

This national network brought together professional artists who performed, exhibited and developed community-based workshops to audiences and community groups via a structure that provided crosscultural brokerage skills. Kultour presented an annual national and (occasional) international touring program in all disciplines of Australian contemporary multicultural arts from 2001 for 11 years. The program supported artists in professional development via opportunities for their work to reach new audiences. In turn, audiences were exposed to a wide range of art practices through a quality professional program. 
In contrast to mainstage arts organisations, which tend to focus on a particular artform (e.g. literature, visual or performing arts), kultour worked with artists from different cultural backgrounds and across all artforms - an ability and burden that is often placed on multicultural arts organisations. Working across all artforms produces a wide range of understandings within a multicultural arts organisation; however, it also heightens the risk of diluting the creative attention given to any one form. This historical pattern of multi-artform multicultural organisations may stem from the low numbers of NESB artists across different artforms, but it reinforces their need for supportive relationships while pursuing an art career.

Initially, kultour comprised an informal national network; however, it soon became a company 'dedicated to the touring of innovative and unique Australian multicultural arts' (Kapetopoulos 2004, 13). Its membership of multicultural arts organisations remained stable between 2001 and 2007 and then grew and evolved. Northern Rivers Performing Arts chaired the network for many years and Multicultural Arts Victoria also played a significant leadership role as the network host by providing space, resources and professional advice. Carmichael $(2011,43)$ observes that, for 'networks to function and be sustained for any length of time, a key issue is that of trust'. Trust needed to accumulate between members and with touring venues, arts organisation and artists. Table 3 identifies the member organisations that established kultour in 2000.

Table 3: Member organisations of kultour in 2000

\begin{tabular}{|l|l|}
\hline Company name & Location \\
\hline Belconnen Community Arts & Canberra, Australian Capital Territory \\
\hline Brisbane Ethnic Music and Arts Centre & Brisbane, Queensland \\
\hline Browns Mart Theatre & Darwin, Northern Territory \\
\hline Kulcha Multicultural Arts of Western Australia & Perth, Western Australia \\
\hline IHOS Opera & Hobart, Tasmania \\
\hline Multicultural Arts Victoria & Melbourne, Victoria \\
\hline NEXUS Multicultural Arts Centre & Adelaide, South Australia \\
\hline Northern River Performing Arts & Lismore, New South Wales \\
\hline
\end{tabular}

Source: Kapetopoulos $(2004,15)$. 
Most of these organisations managed their own venue or had arrangements with partners and presented multi-arts programs. By 2004, the kultour network had expanded to include the NSW Carnivale Multicultural Arts Festival; Casula Powerhouse Arts Centre, Liverpool, NSW; Footscray Community Arts Centre, Victoria; and the Australian Asian Artists Association (Sydney) (Kapetopoulos 2004, 15).

The stated aim of kultour was to expand the professional experience of NESB artists and arts managers through a working relationship based on artistic exchange. The underlying intention was to develop and strengthen trust between state multicultural arts organisations, and to increase their capacity to identify their constituents' needs and straddle their organisational brokering roles. For example, the 2010 national kultour symposium included contributions from practitioners and organisers and raised issues of leadership. Alongside tensions about the benefits or otherwise of mainstreaming-'we should end this multiculturalism business and just be mainstream'-visual artist Khaled Sabsabi articulated the need for activism, claiming that 'arts leadership is a resistance against the way things are' (Anatolitis 2010, 42). The skill of the artist is to play to such contradictory elements; the skill of the network is to navigate them.

Another intention of kultour, as a national body dedicated to improving multicultural arts practice and profile, was to increase the legitimacy of multicultural arts organisations to artists and funding bodies. The knowledge they shared would provide mutual support, increase the profiles of artists and member organisations, and enhance the overall profile of multicultural arts more generally. Kultour thus demonstrated a holistic approach to participation, artist development and audience development (Keating, Bertone and Leahy n.d., 4). Kapetopoulos (2004, 14) found that this required a sophisticated blend of abilities: 'The network is held together by trust and knowledge. As a knowledge network, kultour members exhibit convergent mental models, adept at working in culturally complex environments'.

Each multicultural arts organisation would select artists' works to tour based on agreed quality, level of interest, capacity and logistics at an annual meeting. Touring was considered an opportunity to gauge creative developments in the field. Kultour meetings provided a rare occasion for members to meet face-to-face, raise issues and discuss and develop solutions. A review of the network in its first years conveys some of the complexity of these meetings: 
At meetings, members negotiate between style and genre; contemporary and traditional artforms and hybrids; their understanding of audiences and constituents; communication strategies; timing; presentation modes and most importantly budget. (Kapetopoulos 2004, 16)

Members' support and investment of time and effort stemmed from addressing the practical and perceptual aspects of kultour:

As a touring network it is a good thing-I was surprised when the Australia Council initiated it. Playing Australia has gone down a mainstream path, and we need a touring network which can present quality work of a culturally diverse nature. It is a program which can redress some of the problems of the past in the areas of multicultural arts. When I think of kultour, I visualize quality multicultural arts. (kultour members quoted in Kapetopoulos 2004, 16)

One such 'quality multicultural arts' project, Opposite My House is a Funeral Parlour, was a solo dance piece by dancer and choreographer, Naree Vachananda. In 2006 kultour presented this work in Melbourne, Lismore, Fremantle and Campbelltown. Opposite My House contemplates a journey of death meditating on the Buddhist concept of the cyclical flow of life and death, with the performance structured using the journey of the Greek archetype, Persephone. The artist describes the connections:

The idea of mortality is not only philosophical but also cultural. As a Buddhist trying to collect my thoughts about mortality, I looked at various streams of Buddhism ... I found the Buddhist idea of cyclic flow of life and death was parallel to the myth of Persephone. (Vachananda 2004)

The publicity blurb described it as follows: 'Don't expect black costumes, white powder or saffron transcendence. This dance of death is uncompromisingly contemporary' (MAV 2006b). The work was a collaboration between Darwin-based composer Edward Kelly and multimedia designer Yeap Heng Shen from Malaysia. Author Jenny Joseph permitted the use of excerpts from her book Persephone, reinforcing the cross-cultural foundation of the work.

This dance work is one among many from the range of artforms presented by kultour. It conveys how artists experiment beyond the conventional binary of what constitutes either 'contemporary' or 'traditional' dance. Further, kultour acted as an intermediary, exercising combined 
organisational and creative leadership by delivering audience outreach and workshop presentations. Kulcha (then a Western Australian multicultural arts presenter) enhanced their community audience base and engaged two other companies in Perth and Fremantle, thus extending their cultural credibility and the repertoire and experience of their partners. While in Perth, Vachananda presented a workshop for dancers with the Strut Dance Company and performed in conjunction with Deckchair Theatre Company. The work attracted reviews in RealTime Arts, an arts review broadsheet:

Vachananda is a daring, able choreographer with a strong presence and this work offers a provocative glimpse of the kinds of sustained solo work that can still exist outside the larger streams of dance in Australia. (Baily 2005)

The tour of Opposite My House exemplifies how kultour operated well beyond the norm of the 'fly-in fly-out' tour syndrome.

The next stage of kultour's development aimed to consolidate its role as a partnership broker between artists, major presenters and arts organisations by broadening the skills of its board of directors to include touring expertise and presenter influence. By its very structure, a network is stronger than the sum of its parts. Kultour's use of 'cultural sustainability through industry-based approaches' (Mar and Ang 2015, 23) was characteristic of its broader approach. Adopting an industry-based approach and demonstrating its capacity and legitimacy to manage and direct a tour strengthened the external perception of the organisation. As a national network, kultour also profiled the existence of a multicultural arts sector across each state and territory and enabled a platform for commentary on issues of cultural and political concern (kultour 2011, 2015).

Kultour's platform could not match the strength of other organisations in the industry, in part because the low levels of support afforded to multicultural arts organisation members resulted in a general economic fragility. The 2005 evaluation of AMA 2000 found that, despite the appropriateness of kultour being situated within multicultural arts organisations:

There are inherent tensions when expectations of high quality are located within the context of an under-resourced sector. The funding base of some kultour organisations is precarious at times, where 'survival' issues overtake long-term strategic goals. (Keating, Bertone and Leahy n.d., 4) 
The warning about the loss of small organisations to the network was prescient. Between 2000 and 2015, the number of multi-artform multicultural arts organisations across Australia reduced by over a third, as summarised in Table 4.

Table 4: Longevity of multi-artform multicultural arts organisations

\begin{tabular}{|l|c|c|}
\hline Company name & State & Longevity \\
\hline Footscray Community Arts Centre & Vic. & 1974-present \\
\hline Darwin Community Arts (formerly Brown's Mart) & NT & 1970s-present \\
\hline Carnivale Multicultural Arts Festival & NSW & $1976-2004$ \\
\hline Kulcha & WA & $1983-2013$ \\
\hline NEXUS Arts (formerly NEXUS Multicultural Arts Centre) & SA & $1984-$ present \\
\hline Multicultural Arts Alliance & NSW & $1988-2000$ \\
\hline $\begin{array}{l}\text { Brisbane Ethnic Multicultural Arts Centre (merged with } \\
\text { Queensland Multicultural Centre in 2013) }\end{array}$ & Qld & $1990-$ present \\
\hline Multicultural Arts Victoria & Vic. & $1991-$ present \\
\hline $\begin{array}{l}\text { 4A Centre for Contemporary Asian Arts (previously Asian } \\
\text { Australian Artists Association 4A) }\end{array}$ & NSW & $1996-$ present \\
\hline $\begin{array}{l}\text { Contemporary Asian Australian Performance (previously } \\
\text { Performance 4A) }\end{array}$ & NSW & 1998-present \\
\hline kultour & Vic. & 2000-14 \\
\hline Diversity Arts Australia (advocacy) & NSW & 2015-present \\
\hline Groundswell (advocacy) & NSW & 2011-14 \\
\hline
\end{tabular}

Table 4 shows 11 artform companies producing or presenting multicultural arts. Of these, seven remained in 2015; this represents a 36 per cent attrition rate and demonstrates the dismantling of dedicated creative entry points for many NESB artists. Around 2008, tension regarding the role of kultour came to the fore and continued during its lengthy transition into Diversity Arts Australia (DARTS), which was completed in early 2017. A former kultour manager saw the need to shift responsibility to the wider arts sector because of the exhaustion of doing all the 'heavy lifting' in circulating multicultural artworks (Mar and Ang $2015,110)$. However, the challenges to DARTS are significant because the processes and politics of encouraging other organisations to increase their culturally diverse programming require (at a minimum) resources, influence, cooperation and a substantial change in current risk-averse attitudes. The issue of responsibility for multicultural arts characteristic of institutional settings is also found between organisations that struggle with issues of mainstreaming. This highlights the delicate nature of 
cooperation between creative and organisational leaders. Accompaniment and attunement can be useful processes in assisting this cooperation. To this end, DARTS has utilised social media platforms very effectively to support NESB artists and to increase the listening capacity of arts organisations. The increased access to a wide membership of artists and activists afforded through accessible social media provides DARTS with breakthrough network opportunities.

\section{To Advocate or Practice}

An organisation's ability to adapt to changing environments requires a particular type of responsive and visionary leadership. A former kultour member and Executive Officer of Darwin Community Arts Bong Ramilo (2015, interview) recalls that the Australia Council 'told kultour some years ago that it's no longer an initiative regarding touring'. Kultour was 'told' to transition from a network that linked 'cultural grassroots, the arts field, governance and policy spheres' to a 'new ambit' of advocacy (Mar and Ang 2015, 113).

The move to an advocacy role and away from the creative stimulation that had characterised kultour's remit did not happen lightly. The network resisted its new role, preferring instead to try and manage both roles, grounded in the:

Fusion of quality aesthetic practice and the emergence of different practices and expressions, and using these stories in their arguments for inclusive arts practices that reflect the diversity of Australian society and its cultural contexts. That is perhaps why artist development continues as a key organisational interest, rather than pursuing a purely aesthetically neutral advocacy and service role. (Mar and Ang 2015, 113)

This shift into the politics of advocacy, while valuable, erodes the more difficult role in art production that argues that producing quality art is actually the best advocacy. As Ramilo (2015, interview) (see Image 21) states:

You need to demonstrate that cultural diversity in the arts is a good thing. So me personally, I'd rather just make things. I'd rather have more productions, more recordings, more shows, more booksthat demonstrate that this work is good. 


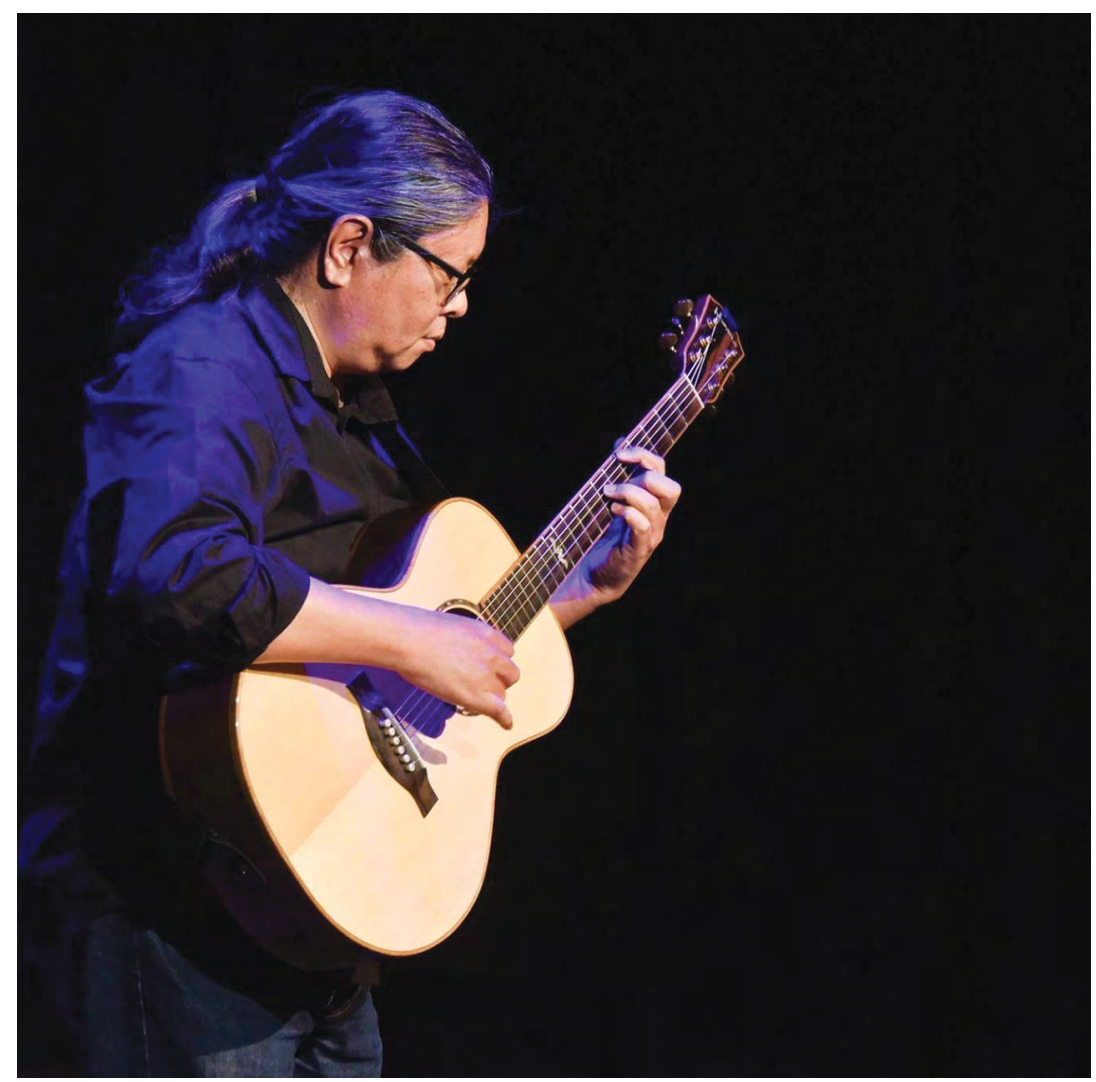

Image 21: Bong Ramilo, Treasure Language Storytelling, performance, 2016

Photographer: Aikuma Project

Part of kultour's role change can be tracked through the different sections of the Australia Council that managed their contract. Executive management decided to 'internally mainstream' the kultour initiative from the AMA policy manager to other departments. This resulted in varying degrees of comprehension by staff as to the needs kultour was meeting and, subsequently, varying responses as to the best approach. The danger of being an initiative of the Australia Council was that kultour was always beholden to them. Compromising with council generated friction between the members:

Multicultural touring should be taken up by the other touring organisations also funded by Australia Council, which of course makes sense-they should be responsive to cultural diversity as well. I heard that Multicultural Arts Victoria, BEMAC [Brisbane 
Multicultural Arts Centre] and Nexus want to set up their own touring circuit, and I support that. They don't think that the other touring organisations will at this point meet all the needs and desires of the companies and artists who want to tour multicultural arts products. I don't know if Performing Lines and the other organisations are really up to it. I don't know how culturally diverse the decision-making bodies of these organisations are or whether they understand the need to represent cultural diversity or not, because I mean it doesn't come automatically. (B. Ramilo 2015, interview)

Performing Lines (PL) is a development, production and touring company for independent Australian performing artists (PL n.d.-a). Ramilo's statement questions the capacity of the 'mainstream' to comprehend and deliver on the aspirations of NESB artists and audience members who may or may not be attracted to, and/or familiar with, their work, and the tensions generated in such interactions.

\section{Mainstream, Tributary or Edge}

If there was adequate infrastructure to produce and present work by NESB artists, one could view the shift in kultour's mission as an important philosophical change that shifted the focus from a 'minority' multicultural sector to diversity across the entire arts sector. Certainly, the multifarious roles are supportive and include all aspects of a creative project from concept to audience response. The multicultural arts milieu would benefit from having a range of multicultural organisations, including ones that produce, tour and advocate. However, in the multicultural arts, it is often an 'either/or' scenario that indicates the limits of that milieu.

Who takes responsibility for, and leadership roles in, multicultural arts have been perennial issues in the arts sector since the 1970s. The low level of support for NESB artists by major companies reinforces the notion that 'mainstreaming' for multicultural practices is not 'automatic', and also highlights issues in the processes of inclusion and organisational leadership. Characteristic tensions for such artists include gaining entry to, and then 'fitting in' with, mainstream arts organisations, or finding creative networks that may have a lower profile but are more supportive. Artists in Far North Queensland, for example, expressed the value of a 'multicultural arts network' to support their 'artistic development' (Babacan 2011, 18). Even though it is expected of them, mainstream 
organisations may not yet have the capability. Ahmed's (2012, 138, original emphasis) comments, although ostensibly about universities, are relevant to mainstream arts organisations:

Mainstreaming, even as an ideal, becomes a problem in the sense that universities are not ready for it: to act as if mainstreaming is the case, because it should be the case, can be counterproductive because the conditions are not available in the present to make it the case.

The issues of timeliness, context and conditions for cultural diversity are necessary precursors before an organisation's values and programs can be considered culturally diverse. Ramilo's statement that 'it doesn't come automatically' respects the myriad knowledges that are in play, at times under tension, within multicultural practices. Georgina Sedgwick of the Darwin Festival reveals how some practices developed and how networks were activated through kultour. These included careful observation and an ability to broker opportunities between artist experimentation, the local community and audience context:

I can't just bring an artist in; get their trust; tour the work, and then after a year the engagement's over. You get to that point where you're a year or two into the engagement and you're just starting to get momentum and see the possibilities. (Sedgwick quoted in Mar and Ang 2015, 108)

In December 2014 kultour's board of directors closed their presence in Melbourne and announced a move to Western Sydney. The state of Victoria has at least two successful arts organisations dedicated to cultural difference: Multicultural Arts Victoria and the Footscray Community Centre. While a move to NSW might address the absence of a dedicated multicultural arts organisation in that state, and could attract different sources of funding, the high calibre of creative and organisational leadership for multicultural artists in Victoria was, arguably, key to kultour's successful functioning. The board responded to the lack of organisational support for culturally diverse artists in NSW by relocating to Western Sydney, an area with a high concentration of NESB artists (Hanna 2012).

Coupled with the remit of national advocacy (probably an impossibility for an under-resourced organisation), the challenge for kultour was to 'encourage' a range of subsidised touring organisations that were resistant to increasing diversity in their programming. In 2015 a multicultural 
arts centre staff and kultour member observed the unwillingness of touring agencies to diversify their marketing or audience. Market driven, such agencies were unconvinced that a market existed for multicultural programming. If one tour was not as successful as expected, the touring agency developed what the staff member described as a 'dampened enthusiasm' to showcase further multicultural artworks.

Another factor is the tension between the desire to remain a marginal artist and the push towards the 'mainstream', as Ramilo observes:

Artists appreciated having an organisation that toured their work because possibly no one else will. No one else appreciated the importance of what kultour did. However, some of us-myself and Aaron Seeto in particular-said we don't want to be part of the mainstream, we like being on the margins. That's an aesthetic thing as well. Some of us don't want to be in the mainstream arts sector automatically. (B. Ramilo 2015, interview)

A previous touring partner, Artback NT, expressed a similar strategic position-namely, that being on the 'margins of things, is a far more interesting place to work' (quoted in Mar and Ang 2015, 111). The relationship between kultour and touring artists reflects trusting negotiations based on knowledge and processes focused on how to tour multicultural arts. This level of intercultural understanding underpins the potential for an artwork to be part of a capacity-building process that goes beyond solely being a presentation. By contrast, established touring companies such as PL develop work to sell into a mainstream arts market. Their website profiles the available work for international and national tours. In 2017 PL developed and promoted some NESB artists for touring: a dance work, A Faint Existence, by performer Kristina Chan; a multimedia work, Crawl Me Blood, by APHIDS; and Layla Majnun by illUMEnate, a performance in development with Western Australian PL Associate Producer Zainab Syed (PL n.d.-b).

These projects suggest that PL has taken up some of the 'heavy lifting' of touring and demonstrates that they value cultural difference in the arts. In later years, touring may form part of their contract with the Australia Council, which, as Ramilo (2015, interview) observes, is 'admirable and legitimate'. However, the mainstage touring approach taken by PL may compromise the extent to which artists can engage with local audiences. The previous description of Vachananda's tour and the reviews of kultour 
highlight the intense labour invested in their touring partnerships that went beyond a scheduled presentation in a particular venue (Kapetopoulos 2004; Keating, Bertone and Leahy n.d.).

The Australia Council's decision to terminate kultour's active touring role and transition it to an advocacy role meant that it was reclassified as a 'service' organisation, which some perceive as the least vital component in the arts system and, therefore, as less crucial in times of financial duress. An estimated 70 per cent reduction in funding to individual artists (Croggon 2016b) occurred in 2016. The S2M sector was also hard-hit and the DARTS (previously kultour) CEO confirmed that it had been 'unsuccessful for 4-year organisational funding announced in 2016' (L. Nahlous 2017, email).

Crucially, the great majority of funding is provided to MPAs. Shakthidharan criticised this Australia Council approach to funding, which assumes that major companies are more 'trustworthy' with funds. This creates the situation-or the perception of a situation-in which multicultural arts organisations with cultural expertise lose funding to major companies who deliver multicultural arts that are more palatable to mainstream audiences. A push-pull tension occurs regarding the value of 'going mainstream'. The risk is that it limits the multiplicities of practice that have characterised multicultural arts in the past and shrinks to a narrow perception of what mainstream companies and their usual audiences consider acceptable.

This case study of kultour exemplifies a history that is littered with the rise and demise of support for Australia's multicultural arts. Kultour was the only national multicultural, multi-artform organisation in Australia. It offered myriad artistic opportunities, including facilitating high-profile national tours of multicultural artworks, promoting creative leadership for artists and facilitating organisational leadership within member organisations. And yet, there was no effective support for kultour to reach its full potential. The legacy of kultour is that supportive relationships between remaining state-based multicultural organisations are in place and they may continue to work together. The structural potential for national multicultural organisational leadership is still viable, albeit in a different form. With this in mind, I argue in the next section that the link between creative production and organisational influence remains the most viable way to generate traction for multicultural arts practices, as exemplified by the partnership between CAAP and PWA. 


\section{Traction Gained through Confluence: Longer-Term Productive Partnerships}

A mission to enter into dialogue with the arts mainstream and broader society formed the mandate of a small arts organisation established in 1996-the Asian Australian Artists Association. The Centre for Contemporary Asian Art (CCAA) is now the visual arts arm of this organisation while CAAP, which became a separate entity in 1998, is the performance arm. In 2015 CAAP began a partnership with PWA, a national company that develops new plays. Both organisations share the aim of developing and producing Asian-Australian performing arts content for the mainstage. The high level of trust established in this partnership generates traction on the mainstage.

\section{Activist Beginnings}

The predecessor to CCAA and CAAP, the Asian Australian Artists Association, also known as $4 \mathrm{~A}$, began in a humble upstairs room in Liverpool Street in Sydney's CBD. The impetus for its establishment was twofold. One motivation was to actively resist the rise of anti-Asian racism emerging in Australia at that time (Ang and Stratton 1998; Hage 2000; Marr 2017). Friction in the sociopolitical environment brought artists together to counter that negativity. Secondly, its creative aims were to promote Asian-Australian art in the context of increasing interest in Asian art and to critique the absence of Asian-Australian artists in the Queensland Art Gallery's inaugural 1996 Asia-Pacific Triennial. The friction between international interest and the lack of recognition by mainstream arts organisations domestically motivated Asian-Australian artists to build an alternative platform. These were 4A's 'unambiguously political and activist origins'; its persistent aim was to be a 'lightning rod' for Asian-Australian and international visual artists, academics and curators (Hore-Thorburn 2017). At the CCAA's twentieth anniversary symposium in late 2016 questions about the centre's relevance resurfaced. Nationalist politician Pauline Hanson had recently been re-elected and the current political climate was described as:

'A far darker situation' indicated by the enormous backlash against cosmopolitanism, diversity, and the ascendency of Trump, the Brexit movement and others. The present situation is in many ways more dangerous than it was in the nineties and more problematic. (Hore-Thorburn 2017) 
One of the roles of organisations such as CCAA and CAAP is to provide counter-narratives to those of mainstream arts organisations and media. CCAA is the only funded visual arts organisation in Australia dedicated to cultural diversity. Its success is attributed, in part, to its artist-centred focus_-or, as visual artist Lindy Lee put it, 'its fidelity to its artists and community' (Hore-Thorburn 2017). Such fidelity may be found within the agility of S2M arts organisations.

\section{The Ripple Effect}

The intense difficulties faced by Asian-Australian performers and live theatre producers, alongside low resourcing levels, to some extent explains why CAAP has taken longer than CCAA to establish itself. CAAP is a small organisation with a barely remunerated executive officer position, many volunteers and philanthropic support for project delivery to increase the number of Asian-Australian performances to reach broad audiences:

CAAP is dedicated to making exceptional contemporary Asian Australian work for all audiences. We engender greater cultural diversity in Australian performing arts by producing cross art form theatrical works of the highest quality, in partnership with major festivals and flagship companies. (CAAP 2017)

Writer, performer, producer, dramaturg, 2021 Artistic Director of the OzAsia Festival and Executive Producer of CAAP Annette Shun Wah (2015, interview) (see Image 22) views the role of CAAP as telling stories and seeing different perspectives that 'examine what it is to be AsianAustralian in contemporary Australia. There's not very much work that reflects or explores that'.

The organisation's strength is its willingness and commitment to band together as a group of Asian-Australian artists, and to connect and match with like-minded creative and entrepreneurial partners. Shun Wah describes the company's influence as one that produces 'ripple' effects through their productions and partnerships. The impact of this 'ripple' both erodes the resistance to cultural diversity demonstrated by larger performance companies and generates the energy to produce more.

While CAAP is a clear example of the benefits of the 'banding together' approach criticised by Shakthidharan, Shun Wah nevertheless shares his view of the role of the activator (an artist who works productively with friction): 
We are only a tiny company, but it's good to be there, to influence and have that ripple effect through the sector. I know I can't do a great deal on my own. Our little company only makes one or two works a year. It's a fantastic effect if we can work with the other people who want to tick that [diversity] box but haven't quite worked out how to do it. (A. Shun Wah 2015, interview)

Shun Wah articulates an alternative perspective on the typically derogatory attitude towards, and assumed tokenism of, 'ticking the box' (DARTS 2017). In doing so, she signals her flexible style of leadership and openness to develop a range of partnerships. Her willingness to assist those who are interested in diversity shows her readiness to engage - a readiness that is likely to be reciprocated. She demonstrates transformational leadership in her charismatic personality, and relational leadership in the relationships that extend from the small organisation. CAAP engenders trust and increases traction when successful works are produced for the mainstage.

CAAP's success is evidenced in the list of its theatre productions programmed by the Sydney and Darwin festivals: In Between Two, The Serpent's Table, Yasukichi Murakami-through a Distant Lens, Stories Then \& Now and Who Speaks For Me? Experienced commercial AsianAustralian artists such as web designers were involved in The Serpent's Table. For many, it was their first opportunity to explore their cultural heritage:

The artists brought their personal backgrounds to the performance and found it so liberating because in the other work they've done until now they haven't been able to utilise any of that. (A. Shun Wah 2015, interview)

Shun Wah's statement points to the issue of creative isolation. AsianAustralian artists do not have a well-established historical record of performances and narratives to draw upon. The lack of a creative history of multicultural, cross-cultural or intercultural arts practices in Australia turns the discourse into a vicious cycle. CAAP, which became a resident company at Carriageworks in 2018, has devised a range of programs aimed at stimulating and sustaining artists and effecting change, including the Asian Australian Performance Directory, the Longhouse Networking Program and the Lotus Playwriting Project; the last undertaken in partnership with PWA (CAAP 2017). This well-crafted suite of programs supports artists in maintaining their creative stamina through professional development and peer support. 


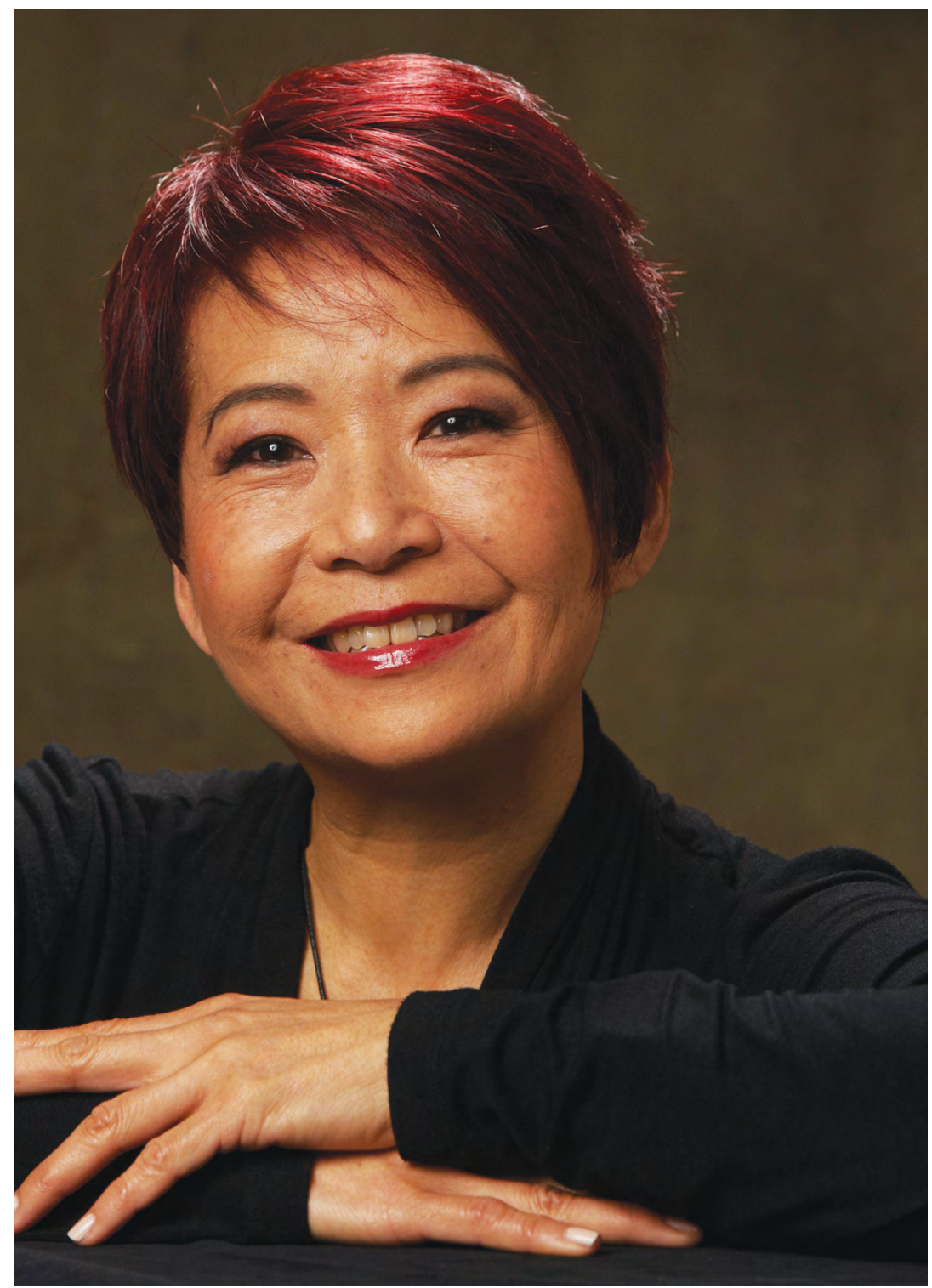

Image 22: Annette Shun Wah

Photographer: Brian Geach 


\section{Fundamental Change: Lotus Playwriting Project}

The partnership between CAAP and PWA reflects UNESCO's 'culture cycles': each stage in the cycle is designed to contribute to culturally diverse art production leading to a final presentation. The work undertaken by CAAP flows through all those processes and addresses a criticism levelled at 'fashionable diversity', whereby 'diversity is restricted to aesthetic presentation, rather than a meaningful, committed, resourced, long-term process of shifting existing power-dynamics' (Canas 2017).

The shift in the arts towards increasingly diverse presentations requires structural change that is deemed to 'take a long time', according to CAAP's partner on the Lotus Playwriting Project (Lotus), PWA's Artistic Director, at the time, Tim Roseman:

Our plays are very white, very middle class. Last year [2013] there were six plays on the Australian stage not written by white people. Every company I speak to is itching to put on a play by that Cambodian-Australian playwright, but it isn't there. (Radio National 2014)

Roseman's insights and enthusiasm are genuine and demonstrate elements of organisational leadership. However, the trope of time-'we want to make a fundamental change, but it will, of course, take time'-mitigates against the processes to make that change (Radio National 2014). Roseman appears to accept his colleagues' ignorance regarding structural problems captured by their 'itching to put on' what 'isn't there'. His colleagues may have been irritated by their lack of contemporary programming regarding that 'Cambodian-Australian playwright', but they neither took responsibility for the fact that they could not find such a play nor attempted to address the situation. Roseman saw a gap in the market that PWA could address, but he needed an expert partner-CAAP.

Lotus nurtures a new generation of Asian-Australian writers to address the low numbers of their published plays, which, currently, can be counted on 'the fingers of one hand' (A. Shun Wah 2015, interview). It develops the artists' trust in themselves via increased confidence and peer support. When their work reaches a certain stage, producers from mainstage organisations are able to trust their work and begin to work with those writers. In under a year, Lotus generated play readings from 12 writers at Brisbane's La Boite Theatre, Melbourne's Malthouse Theatre and Parramatta's Riverside Theatre. Shun Wah is confident that the 
combined programs run by CAAP will have another 12 completed, fulllength plays by Asian-Australian writers in under three years (A. Shun Wah 2015, interview).

One aspect of a culture cycle is the research and development phase. Preparatory phases are needed to gain the interest and commitment of writers of Asian-Australian backgrounds to attend the program. The partnership between CAAP and PWA has been successful in part because the leaders of both organisations are committed to changing the face of Australian performance and because they straddle roles of creative development and service organisations. The following description of PWA could equally apply to CAAP: 'I think we're an artistic-led company, servicing the rest of the industry by providing them with amazing new plays' (T. Roseman 2015, interview).

This synergy deepens when Shun Wah's and Roseman's skills combine to work 'across cultures'. Roseman brings experience from the United Kingdom, which he sees as probably a 'good generation or so ahead of what's happening in Australia because they are moving away from the deficit model' (T. Roseman 2015, interview). PWA employ culturally diverse staff and uses a process of decision-making for programming that engages with artists of relevant cultural backgrounds. This collaborative approach is also evident in their business planning:

In our last [strategic plan], we had a section called 'our diversity projects' and I've taken that out because as long as you have your work and your diversity work, you're silo-ing and you're still living in the realm of otherness. So we make a statement that all of our projects speak to cultural, linguistic, social, political, regional diversity. (T. Roseman 2015, interview)

This statement encapsulates the organisation's commitment to diversity and its plans for long-term change. When applying a 'diversity' label, PWA maintained such projects' status as a sidebar, an add-on. Changing its mission statement may assist the company to translate its plans into action, as expressing intention can activate 'hopeful performative' attention (Ahmed 2012, 67).

Roseman also knows that 'cultural parity [is yet to be achieved, and that PWA needs to] create programs that speak directly' to particular marginalised groups (T. Roseman 2015, interview). Further, he acknowledges the expertise that CAAP brings to delivering PWA's aims. 
For example, whereas there was a poor response to a call-out by PWA for Asian-Australian artists to attend a workshop on playwriting, when CAAP did their call-out for the inaugural Lotus Project, over 30 people attended, and these numbers were replicated across capital cities. CAAP engages across a wide artistic spectrum that includes 'writers, bloggers, poets, actors, musicians' (A. Shun Wah 2015, interview). According to Roseman (2015, interview), 'the only rule of theatre is that content dictates form', which, for Lotus, relieves the pressure of making multicultural stories fit into what might be a mainstream canon or aesthetic. The style of the performance of the work will depend on the content that is being explored. Both parties, therefore, are bringing an open perspective to the playwriting process, which directly benefits the presentation outcomes.

An early presentation phase for Lotus is PWA's annual Playwriting Festival, which, in 2016, included four play readings developed through the Lotus program: Site Rubiyah by Katrina Irawati Graham, Squint Witch by Shari Indriani, My Father Who Slept in A Zoo by Ngoc Phan and Entomology by Natesha Somasundaram (PWA 2016). As well as delivering CAAP and PWA's joint aims for long-term change, crucially Lotus also highlights how creative capacities can build relatively quickly. The 2015 Lotus Project in Brisbane had works picked up by niche theatre company La Boite, new writing theatre Playlab and the mainstage Queensland Theatre Company-'even before we finished the second stage' (A. Shun Wah 2015, interview). Blue Bones, written by Merlyn Tong, was presented by Playlab and later won six Matilda Awards for Queensland theatre, including the Brisbane Lord Mayor's best new Australian work (Matilda Awards 2017). While the ensuing publicity could have acknowledged CAAP more roundly, successes such as these have placed their processes in the spotlight and are likely to inspire others. They challenge the it will take time' trope.

Industry accolades notwithstanding, the lack of tertiary recognition or accreditation for such informal professional development is a potential risk. Shun Wah responds to such concerns by pointing out the lack of playwriting courses in Australia and the lack of cultural depth on the curriculum. Professional training streams, where they do exist, tend not to engage in multicultural content development. Many NESB artists in tertiary education undertake parallel training, seeking out content that resonates and could lead to career opportunities. Some Asian-Australian artists who have completed courses at the National Institute of Dramatic Arts (NIDA), for example, also use Lotus in their careers: 
When I talk to students, who come fresh out of NIDA or wherever, they're full of optimism after just graduating, and don't think they need to bear the culturally diverse tag because they know they're smart and talented. But about two years later they come back [to me], having realised the opportunities that rightfully should be theirs, are not there. (A. Shun Wah 2015, interview)

Lotus is unique because it steps the writer through as many stages of development as possible: from writing to non-professional/professional readings to industry presentation. Recognising the value of Lotus, a philanthropic foundation committed three years of support. This will ensure program delivery and freedom from the rigours of grant applications for Australia Council and other funding with their associated criteria and constraints. The foundation's support will enable Lotus to be an 'in-depth, longer term, serious intensive workshopping and mentoring' program (A. Shun Wah 2015, interview) (see Image 23). Nevertheless, CAAP's low levels of remuneration serve to maintain the performing arts' inequitable power structure. CAAP creates content that is taken up by companies that are funded to present such work, but who do not (necessarily) contribute financially to CAAP's processes. In this way, well-resourced companies reap the benefits without (necessarily) contributing to the research and development processes of the playwright. It is philanthropic support to CAAP that enables the Lotus workshops to 'ripple through' the arts.

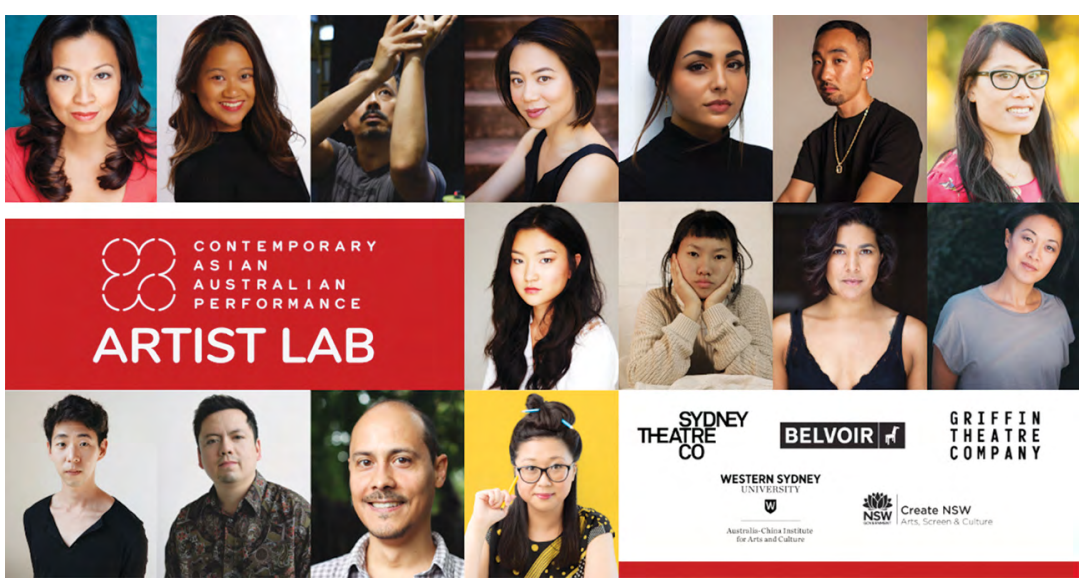

Image 23: Contemporary Asian Australian Performance Artists Lab brochure, 2020

Courtesy: Contemporary Asian Australian Performance 


\section{A Virtuous Cycle}

The creative success of Lotus extends beyond the initial bipartisan partnership, delivering several phases in the culture cycle across many arts organisations. That joint vision extends the capabilities for CAAP and PWA to generate an engagement beyond the occasional, one-off experience. In this way, Lotus has led a virtuous cycle to increase the production of multicultural arts, the phases of which can be described as: artist $>$ CAAP identifies a viable creative process for change $>$ PWA recognises a diversity gap and seeks ways to address it $>$ CAAP and PWA in partnership > initial play development $>$ workshops $>$ play reading by professional actors and directors $>$ showcase to performing arts industry $>$ selection by mainstage $>$ public presentation $>$ possible national or regional tour $>$ increased profile of artists and companies $>$ increased relevance to diverse audiences $>$ contribution to a multicultural arts milieu > more Asian-Australian artists are involved. (See Appendix E for a graphic representation of this organisational change cycle.)

This cycle draws on relational and transactional leadership and uses the skills of attunement and accompaniment to develop an alternative trajectory in the Australian arts. The cycle depicts the practical outcomes when creative and organisational leadership work in concert. In the case of Lotus, the initial partnership seeks to widen Asian-Australian artists' capacity to link directly with 'industry' or the mainstage. Alongside Roseman's critical assessment of the situation in Australia, Shun Wah's leadership drives Lotus with skill, patience and perseverance:

Big companies are now seeking our partnership or collaboration. The aim is for the entire sector, all of us, to respond and learn how to be more culturally diverse in what we do. To create work that's more relevant to the Australian society as it is today and, in doing that, maybe attract more diverse audiences. (A. Shun Wah 2015, interview)

Shun Wah's relational leadership is tangible. She creates opportunities for other artists beyond her immediate sphere and through CAAP programs on the mainstage. Her experience is also tangible—she has been working in the area of multicultural performance, presentation and writing since the mid-1980s, and draws on that experience to ensure long-term change. As such, she brings her extensive knowledge and experience as a cultural and creative broker to envisage, promote and enact change. In 2018 
CAAP became a resident company at Carriageworks, which provides stable accommodation and a high-profile venue for their programs (Taylor 2017).

Despite their active partnership in changing the multicultural arts milieu, neither Shun Wah nor Roseman expressed a close link to the Australia Council's Cultural Engagement Framework (CEF) or arts policy. Because of her long-term engagement with multicultural arts practices, Shun Wah (2015, interview) is aware of the AMA policies, the loss of companies such as Carnivale and the retreat from multiculturalism as a government focus, which:

Got replaced for a while by a push towards youth arts and so suddenly the big focus was on a lot of stuff for young people, which was fantastic. But then it's as if you can only deal with one priority at a time. And I think, as a nation, we could be a bit more sophisticated than that.

Shun Wah's vision for a multicultural arts milieu is one that extends across age, socio-economic and cultural backgrounds. To be sophisticated suggests a more complex conversation and exploration of how diversity is 'circulated' (Ahmed 2012, 81). Facilitating the circulation of creative diversity occupies Shun Wah and Roseman outside the realms of policy:

I've never had a conversation about arts policy with any practitioner in the two and a half years that I've been in this job. A real problem regards the conditions of funding. The Australia Council believes that it's up to arts companies to decide what they want to do and how to spend their money. I firmly believe in quotas and not incentives. (T. Roseman 2015, interview)

Echoing debates articulated earlier between Marinos and Klika, Roseman identifies the combative friction between legislating for change and laissezfaire. He wants funding to be dependent on an organisation's strategies to alter the 'white hegemony of this culture, [which] is way more important than ... risk management or marketing' (T. Roseman 2015, interview).

A cause for concern for Shakthidharan is the increasing direction of funds towards mainstage organisations-particularly given those organisations' risk-averse track record in terms of generating distinctive multicultural artworks. The Australia Council has adopted an incentive approach with regard to the MPAs; it offers a grant that only MPAs are eligible to apply for and requires them to deliver on one of the diversity options across 
the CEF. This apparent disregard for small multicultural organisations may go deeper. As a consequence of shrinking support to multicultural organisations, the ability of the next generation of NESB artists to gain the experience necessary to keep the multicultural arts baton active and in circulation will be severely limited.

The demographic context is changing rapidly in Australia. The country's increasingly culturally diverse population implies that what the 'multicultural arts sector' means today cannot be the same as in the 1980s. CAAP and PWA demonstrate an agile ambitiousness that responds to opportunities in the current society for Asian-Australian performance and opens up possibilities in a structured and detailed approach that is also fluid and creatively responsive to the interests of artists. This form of relational leadership can be seen in both Shun Wah's and Roseman's leadership styles, yet is differently nuanced. Shun Wah's version may be slightly more attuned, as she helps to bring the creative material into reality, while Roseman's may be more linked to accompaniment, as the steps taken lead towards presentation on stage. In these ways, a 'community takes shape through the circulation of diversity' (Ahmed 2012, 81) that expands the possibilities available in a multicultural arts milieu.

\section{Conclusion}

Artists and organisations take up a leadership mantle to devise new ways of working for, and in, the production and presentation of multicultural arts. Their methods of working combine both creative and organisational forms of leadership, whereby an exchange of knowledge occurs between artist, cultural broker and organisation. I argue that both creative leadership and organisational leadership working in tandem are pivotal to any new social and civil contract, and these need to be led by NESB artists who are essential contributors to a multicultural arts milieu. Creative leadership improves diverse art production and organisational leadership improves its dissemination; when working in concert, they extend those outcomes across each segment of the arts. Processes such as 'attunement' (Gibson 2005) and 'accompaniment' (Lynd and Lynd 2009) enable attentiveness that extends the modes of leadership. The observation that, in 'being spoken, and repeated in different contexts, a world takes shape around diversity' (Ahmed 2012, 81), contributes to the relational style of leadership most suited to achieve those outcomes. Ahmed articulates 
a principle relevant to an expanding multicultural arts milieu: that uptake needs to occur across the range of arts organisations and artists. However, multicultural arts practice can be a tremulous zone that spins on the head of a pin and requires persistent pushing into place. It is through the intercultural artistic processes used by NESB artists that increased participatory outcomes for diversity are shaped. Through the shared processes found in the modes of relational and distributed leadership, the arts can participate in the 'creation of a world'. 
This text is taken from Creative Frictions: Arts Leadership, Policy and Practice in Multicultural Australia, by Cecelia Cmielewski, published 2021 by ANU Press, The Australian National University, Canberra, Australia.

doi.org/10.22459/CF.2021.06 